Research Article

\title{
A Study to Assess the Psychological Status, Social and Health System Support to the Women who are Undergoing Infertility Treatment
}

\author{
Deepika Pawar', Bindu Shaiju², Fareha Khan ${ }^{3}$
}

${ }^{1}$ M.Sc. Nursing Student, ${ }^{2}$ Associate Professor, ${ }^{3}$ Assistant Professor, Rufaida College of Nursing, Jamia Hamdard, New Delhi, India. DOI: https://doi.org/10.24321/2455.9318.202012

\section{I $\quad \mathbf{N} \quad \mathbf{F} \quad \mathbf{O}$}

\section{Corresponding Author:}

Bindu Shaiju, Rufaida College of Nursing, Jamia Hamdard, New Delhi, India.

E-mail Id:

bindushaiju07@yahoo.co.in

Orcid Id:

https://orcid.org/0000-0002-2574-9160

How to cite this article:

Pawar D, Shaiju B, Khan F. A Study to Assess the Psychological Status, Social and Health System Support to the Women who are Undergoing Infertility Treatment. Int J Nurs Midwif Res 2020; 7(2): 11-15.

Date of Submission: 2020-06-17

Date of Acceptance: 2020-11-10

\section{$\begin{array}{llllllll}\mathbf{A} & \mathbf{B} & \mathbf{S} & \mathbf{T} & \mathbf{R} & \mathbf{A} & \mathbf{C} & \mathbf{T}\end{array}$}

Introduction: Infertility is not only a gynecological illness but also a biopsycho-social health problem including a lower Quality of Life (QOL), psychiatric problems, marital conflicts and sexual dissatisfaction. Women in India are facing the burden of infertility treatment because of cultural and social stress, lack of knowledge and which can lead to other mental health problems.

Objectives: The study aimed to assess the psychological status including the anxiety and depression, level of social support by family spouse and peer, and to assess the level of health system support by doctors, nurses and any health care provider to the women who are diagnosed with primary infertility.

Methodology: Quantitative (non-experimental) approach was used. The data was collected from select 80 women who were undergoing infertility treatment at National Institute of Health and Family Welfare, New Delhi. A standardized scale (BAI and BDI) was used to assess the psychological status and structured questionnaire to assess the social support and health system support among the women in view of getting infertility treatment support for data collection and later data was analyzed using descriptive statistics.

Result: The findings revealed that $28.75 \%$ were normal and $28.75 \%$ had moderate level and $10 \%$ had severe level of depression, $93.75 \%$ had low level of anxiety, $5 \%$ had moderate level of anxiety and $1.25 \%$ had extreme level of anxiety, the $80 \%$ were getting average, $11.25 \%$ getting poor and $8.75 \%$ were getting good social support. $96.25 \%$ women were getting good support, $1.25 \%$ were getting average support and $2.5 \%$ were getting poor support from the health system.

Conclusion: The study concluded that women who are undergoing infertility treatment had faced moderate mood disturbances as well less support from the family and spouse in their life. Further research must be undertaken to investigate better management for psychological and emotional support techniques to surpass their problem and you are valuable with or without a baby.

Keywords: Infertility, Primary Infertility, Anxiety, Depression, BAI, BDI 


\section{Introduction}

The International Committee Monitoring Assisted Reproductive Technologies (ICMART) defines Infertility is "a disease of the reproductive system defined by the failure to achieve a clinical pregnancy after 12 months or more of regular unprotected sexual intercourse. There are two types of infertility - primary and secondary: Primary infertility method that the couple has by no means conceived. Secondary infertility approach that the couple has experienced a pregnancy earlier than and failed to conceive later. ${ }^{1}$

Infertility is not only a gynecological illness but also a biopsycho-social health problem including a lower Quality of Life (QOL), psychiatric problems, marital conflicts and sexual dissatisfaction. Stigmatization, loss of potency, role failure, and reduced self-esteem are negative results of infertility. Feelings of personal and sexual inadequacy, sexual dysfunction, depression, anxiety, hostility, and guilt have been reported. ${ }^{2}$

According to the World Health Organization estimate, the overall incidence of number infertility in India is between 9 to $16 \%$. In Indian states, incidence of infertility varies in different parts of the country with $3.7 \%$ in Uttar Pradesh, Himachal Pradesh and Maharashtra, to 5\% in Andhra Pradesh, and $15 \%$ per cent in Kashmir and occurrence varies in identical place across tribes and caste. ${ }^{3}$

\section{Material and Methods}

The research approach selected for the study was quantitative, non-experimental. A survey design was used to assess the psychological status, social and health system support to the women who are undergoing infertility treatment. A total of 80 women were selected by purposive sampling technique, who were diagnosed with primary infertility and getting treatment at National Institute of Health and Family Welfare, New Delhi. Women who met the inclusion criteria i.e. women diagnosed with primary infertility, willing to participate in the study, women falling in the age group of 20-45 years, women able to read and write English and women who will be available at the time of data collection were enrolled for the study. There was no attrition and contamination of samples.

The tools used for data collection comprised of four sections Section I: Consist of questions related to demographic data such as age, educational status, religion, monthly family income, duration of infertility. Section II: Standardized Beck Anxiety and Depression inventory to assess the psychological status to women who are undergoing infertility treatment.

Part A - Beck Depression Inventory in view of women being diagnosed with primary infertility. It consists of 21 points; each point contains a number of statements. The respondent selects the one that best describes health in view of being diagnosed with primary infertility, during the past two weeks including today.

Part B - Beck Anxiety Inventory in view of women being diagnosed with primary infertility. It consists of common symptoms of anxiety. The respondent how much have been bothered by that symptom during the past month, including today, in view of being diagnosed with primary infertility by circling the number in the corresponding space in the column next to each no. of items.

Section III: Structured questionnaire to assess the Social support, divided into three subparts as follows:

- Part A - Consist of family support to women who were undergoing infertility treatment

- Part B - Consist of spouse support to women who were undergoing infertility treatment

- Part C - Consist of peer support among women who were undergoing infertility treatment.

The tools were validated by giving it to 7 experts from the field of Psychiatric, Obstetrics and Gynecology and Nursing. The reliability of the tool was assessed by using Cronbach's Alpha Formula and was found to be 0.78 . The tool was proved to be reliable. After obtaining ethical permission from the IEC and permission from the administrative authority of National Institute of Health and Family Welfare, the selected sample was informed about the procedure of data collection and their informed consent was taken. The tools were administered on the sample and the data collected were analyzed using descriptive statistics.

\section{Result}

\section{Section I: Description of Sample Characteristics}

The study findings revealed that out of the 80 women who are undergoing infertility treatment $51.25 \%$ of women were in the age group of 25 to 30 years getting the treatment of infertility, $35 \%$ of women were graduate and $73.75 \%$ women belong to Hindu religion who are undergoing infertility treatment, $86.25 \%$ of women had monthly family income between Rs. 25000-30000. Most of the women who were getting infertility treatment were married for 1-5 years seeking medical advice of primary infertility in the National institute of health and family welfare.

Table I.Frequency and percentage distribution of women undergoing infertility treatment based on the level of depression

$(n=80)$

\begin{tabular}{|c|c|c|}
\hline Level of depression & Frequency & Percentage (\%) \\
\hline $\begin{array}{c}(0-10) \text { Normal mood } \\
\text { disturbances }\end{array}$ & 23 & 28.75 \\
\hline $\begin{array}{c}\text { (11-16) Mild mood } \\
\text { disturbance }\end{array}$ & 10 & 12.5 \\
\hline
\end{tabular}




\begin{tabular}{|c|c|c|}
\hline $\begin{array}{c}\text { (11-16) Mild mood } \\
\text { disturbance }\end{array}$ & 10 & 12.5 \\
\hline $\begin{array}{c}\text { (21-30) Moderate } \\
\text { depression }\end{array}$ & 23 & 28.75 \\
\hline $\begin{array}{c}\text { (31-40) Severe } \\
\text { depression }\end{array}$ & 8 & 10 \\
\hline $\begin{array}{c}\text { (over 40) Extreme } \\
\text { depression }\end{array}$ & 3 & 3.75 \\
\hline
\end{tabular}

Section II: Finding Related to the Psychological Status of Women who are Undergoing Infertility Treatment

Table 2.Frequency and percentage distribution of women undergoing infertility treatment based on the level of anxiety

$(n=80)$

\begin{tabular}{|c|c|c|}
\hline Level of anxiety & Frequency & Percentage (\%) \\
\hline (0-21) low anxiety & 75 & 93.75 \\
\hline $\begin{array}{c}\text { (22-35) moderate } \\
\text { anxiety }\end{array}$ & 4 & 5 \\
\hline $\begin{array}{c}\text { (Score of 36 and } \\
\text { above) severe level of } \\
\text { anxiety }\end{array}$ & 1 & 1.25 \\
\hline
\end{tabular}

Table 3.Frequency and percentage distribution of women undergoing infertility treatment based on the level of social support

$(n=80)$

\begin{tabular}{|c|c|c|}
\hline $\begin{array}{c}\text { (Score) Level of social } \\
\text { support }\end{array}$ & Frequency & Percentage (\%) \\
\hline (0-20) Poor support & 9 & 11.25 \\
\hline (21-40) Average support & 64 & 80 \\
\hline (41-60) Good support & 7 & 8.75 \\
\hline
\end{tabular}

Table 4.Frequency and percentage distribution of women undergoing infertility treatment based on the level of health system support

$(n=80)$

\begin{tabular}{|c|c|c|}
\hline $\begin{array}{c}\text { (Score) Level of health } \\
\text { system support }\end{array}$ & Frequency & Percentage (\%) \\
\hline (0-6) Poor support & 2 & 2.5 \\
\hline (7-13) Average support & 1 & 1.25 \\
\hline (14-20) Good support & 77 & 96.25 \\
\hline
\end{tabular}

\section{Discussion}

The present study showed that $28.75 \%$ of female had normal mood and also $28.75 \%$ of women had moderate level of mood disturbances, and $16.25 \%$ having borderline clinical symptoms of depression and $93.75 \%$ women having low level of anxiety and only $1.25 \%$ score 36 and above shows the severe level of anxiety. Contrary to these findings, a cross-sectional study by Lykeridoua $\mathrm{K}$, et al. ${ }^{4}$ found that women having low level of stress related to infertility, low score of depression but higher score of anxiety than the normative score.

Present study findings also indicated that $11.25 \%$ of women had poor support, $80 \%$ women getting average support and $8.75 \%$ getting good support from society. Similarly to the present study, Jafarzadeh-Kenarsari F et al. ${ }^{5}$ did a qualitative study based on a content analysis approach. The infertile couples were selected from patients attending public and private infertility treatment centers and private offices of infertility specialists in Isfahan and Rasht, Iran and data revealed four main categories of infertile couples' needs, including: i) Infertility and social support, ii) Infertility and financial support, iii) Infertility and spiritual support and iv) Infertility and informational support.

With regard to the health system support, the present study findings revealed that $96.25 \%$ of women getting good support, $2.5 \%$ were getting poor support. In contrast to present study, an exploratory study by Yebei VN6 was conducted to assess the unmet needs and attitudes of women between age group 15-44 years with infertility problems in selected areas of Ghana where the study revealed that $32 \%$ of women experience.

\section{Implication of the Study}

The finding revealed that women having infertility had faced normal to moderate mood as well as mild levels of anxiety in their life. Therefore, the study findings have implications in various fields of nursing including counseling of couples, support them to initiate their choice, encourage them to talk out their queries and the implications in nursing practice, nursing education, nursing research and nursing administration.

\section{Nursing Practice}

The nursing personnel should be well equipped with knowledge, skills and positive attitude to assess the level of social and health care system support while dealing with couples having infertility and related psychological problems.

Nurses should be able to assess the coping strategies used by the women having infertility to deal with the life situations and teach them effective coping strategies in dealing with the problem they faced as a result of psychological issues related to infertility.

The nurse should be aware of the resources available in the health care unit and couples having anxiety and depression and lack of social support due to infertility can seek help so that they are able to cope up with psychological issues. The 
nurse can serve as a liaison between these health care unit resources and couples having infertility with psychological issues. These health care unit resources can serve care by counseling services, family therapies, telephone helplines and self-help groups.

\section{Nursing Education}

The findings of the study indicate that more emphasis should be placed in the nursing curriculum on infertility. Nurses can utilize their communication skills, knowledge, skills, experience to guide or counsel the clients who are suffering from infertility. Therefore, the curriculum must include aspects on care for infertile women.

Nursing education must focus its attention in preparing mental health nurses as a graduate and post graduate level in such a way that they will be able to care for couples having anxiety and depression, lack of social and health care system support related to infertility.

Nursing curriculum should include practical guidance and counseling of couples having anxiety and depression, lack of social and health care system support related to infertility. The focus of guidance and counseling should be mainly the promotion of mental health of couples having anxiety and depression related to infertility.

Nursing curriculum must give priority to prepare the nurses in identifying the needs of and conduct needs based health education programs for couples regarding management of anxiety and depression in a variety of settings such as family community hospitals and other health care agencies.

\section{Nursing Research}

Psychological problems related to infertility are an emerging area of concern for all the couples having infertility. Distress is the experience of overwhelming anxiety or suffering due to infertility. Research shows that the main source of mood disturbance for clients having infertility is the impact of infertility on their social life, their sexual health and their relationship with their partner. It remains researchable area for all types of professionals such as psychologists, nurses, gynecologists and sociologists.

\section{Nursing Administration}

Provision should be made to have full-time counselors' trend in counseling in hospitals and healthcare units exclusively for couples having infertility and for their family members.

Nursing personnel should be motivated to devote their time for the development of education material like informational booklet, leaflet, pamphlet, especially on management of infertility.

Provision should be made for easy access of clients to educational material of information which are already developed and easy to follow as well as implanted.

\section{Limitation}

The sample size was small and particularly in a specific institute. Therefore, generalization of study cannot be done.

Obtaining the desired sample within a limited time period was a little difficult for the researcher.

\section{Conclusion}

On the basis of results of data analysis, the following salient conclusions were drawn that women who are undergoing infertility treatment faced normal to moderate mood disturbances and less support from the family and spouse in their life. Further research must be undertaken to investigate better management for psychological and emotional support techniques to surpass their problem as women are valuable with or without a baby.

\section{Acknowledgement}

I am obliged to express my gratitude to Prof. (Dr.) Manju Chhugani, Dean, School of Nursing Science and Allied Health, for facilitating permission, extending facilities, support and consistent help throughout this research project.

I extend my grateful thank to Prof. Urmila D. Bhardwaj, Principal, Rufaida College of Nursing, Jamia Hamdard for encouragement, timely suggestions throughout my research work

I express my deep sense of gratitude and indebtedness to my mentor Ms. Bindu Shaiju Associate Professor, Rufaida college of Nursing, for their support, esteemed guidance, during my research endeavor. Words cannot express my very profound gratitude and love to my parents Mr. L. N Pawar and Mrs. Prabha for their unconditional love and support. I am profoundly in-debited to all experts who contributed their time and efforts towards validating and refining tools used in present study.

\section{Conflicts of Interest: None \\ References}

1. International Committee for Monitoring Assisted Reproductive Technology (ICMART) and the World Health Organization (WHO) revised glossary of ART terminology. Sexual and Reproductive Health 2009; 92(5): 1520-1524.

2. Petok WD. The psychology of gender-specific infertility diagnosis. In Maternity, Newborn and Women's Health Nursing 2008; 2: 37-60.

3. World Health Organization. Challenges in reproductive health research. Biennial report of Geneva, 2000. 
4. Lykeridou K, Gourounti K, Deltsidou A et al. The impact of infertility diagnosis on psychological status of women undergoing fertility treatment. Journal of Reproductive and Infant Psychology 2009; 27(3): 223-237.

5. Jafarzadeh-Kenarsari F, Ghahiri A, Habibi M et al. Exploration of infertile couples' support requirements: a qualitative study. Int J Fertil Steril 2015; 9(1): 81-92.

6. Yebei VN. Unmet needs, beliefs and treatment-seeking for infertility. Repro'd Health Matters 2000; 8(16): 34-41. 